PREPARED FOR THE U.S. DEPARTMENT OF ENERGY, UNDER CONTRACT DE-AC02-76CH03073

PPPL-3992

PPPL-3992

UC-70

Accounting of the Power Balance

for Neutral-beam Heated H-mode Plasmas

in NSTX

by

S.F. Paul, R. Maingi, V. Soukhanovskii, S.M. Kaye,

$\mathrm{H}$. Kugel, and the NSTX Research Team

August 2004

NM|

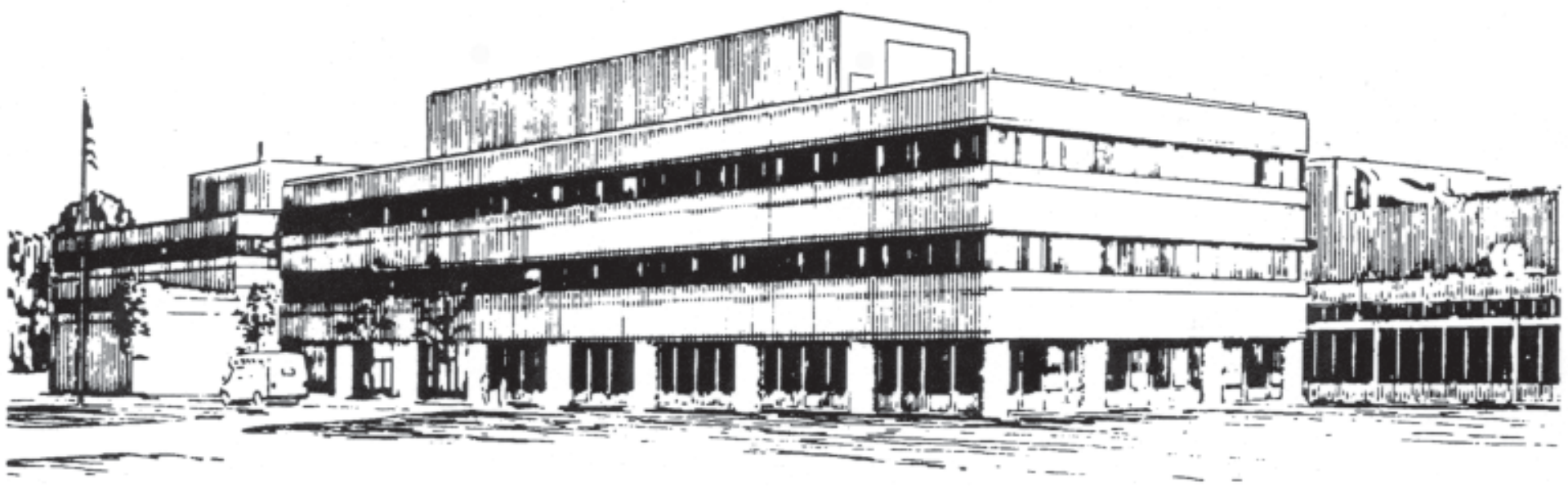

PRINCETON PLASMA PHYSICS LABORATORY PRINCETON UNIVERSITY, PRINCETON, NEW JERSEY 


\section{PPPL Reports Disclaimer}

This report was prepared as an account of work sponsored by an agency of the United States Government. Neither the United States Government nor any agency thereof, nor any of their employees, makes any warranty, express or implied, or assumes any legal liability or responsibility for the accuracy, completeness, or usefulness of any information, apparatus, product, or process disclosed, or represents that its use would not infringe privately owned rights. Reference herein to any specific commercial product, process, or service by trade name, trademark, manufacturer, or otherwise, does not necessarily constitute or imply its endorsement, recommendation, or favoring by the United States Government or any agency thereof. The views and opinions of authors expressed herein do not necessarily state or reflect those of the United States Government or any agency thereof.

\section{Availability}

This report is posted on the U.S. Department of Energy's Princeton Plasma Physics Laboratory Publications and Reports web site in Fiscal Year 2004. The home page for PPPL Reports and Publications is: http://www.pppl.gov/pub_report/

DOE and DOE Contractors can obtain copies of this report from:

U.S. Department of Energy

Office of Scientific and Technical Information

DOE Technical Information Services (DTIS)

P.O. Box 62

Oak Ridge, TN 37831

Telephone: (865) 576-8401

Fax: (865) 576-5728

Email: reports@adonis.osti.gov

This report is available to the general public from:

National Technical Information Service

U.S. Department of Commerce

5285 Port Royal Road

Springfield, VA 22161

Telephone: $1-800-553-6847$ or

(703) $605-6000$

Fax: (703) 321-8547

Internet: http://www.ntis.gov/ordering.htm 


\title{
Accounting of the power balance for neutral-beam heated H-mode plasmas in NSTX
}

S.F. Paul*, R. Maingi ${ }^{a}$, V. Soukhanovskii ${ }^{b}$, S.M. Kaye, H. Kugel, and the NSTX Research Team

\author{
Princeton Plasma Physics Laboratory, Princeton, NJ, USA \\ ${ }^{a}$ Oak Ridge National Laboratory, Oak Ridge, TN, USA \\ ${ }^{b}$ Lawrence Livermore National Laboratory, Livermore, CA, USA
}

A survey of the dependence of power balance on input power, shape, and plasma current was conducted for neutral beam heated plasmas in NSTX. Measurements of heat to the divertor strike plates and divertor and core radiation were taken over a wide range of plasma conditions. The different conditions were obtained by inducing an L-mode to H-mode transition, changing the divertor configuration [lower single null (LSN) vs. double-null (DND)] and conducting a NBI power scan in H-mode. Up to $70 \%$ of the net input power is accounted in the LSN discharges with $\approx 20 \%$ of power lost as fast ions, $\approx 30 \%$ incident on the divertor plates, $\approx 10 \%$ radiated in the core, and $\approx 10 \%$ radiated in the divertor. In contrast, the power accountability in DND is $85-90 \%$. A comparison of DND and LSN data show that the remaining power in the LSN is likely to be directed to the upper divertor.

JNM Keywords: Plasma Properties, Plasma-Materials Interaction, Impurities, Divertor Materials

PSI16 Keywords: Divertor, Edge Plasma, Power Balance, NSTX

PACS: $52.40 . \mathrm{H}, 52.55 \mathrm{Fa}$

*Corresponding author: S. F. Paul

*Corresponding author address: Princeton Plasma Physics Laboratory, U.S. Route \#1 North, Princeton, NJ 08543-0451

*Corresponding author tel: +1-609-243-3781

*E-mail address: spaul@pppl.gov (S. F. Paul)

*Presenting author: S. F. Paul 


\section{Introduction}

One of the features of the small major radius specific to spherical tokamak designs is the likelihood of high heat flux to divertor target surfaces. This paper presents results from a recent power balance scaling experiment on National Spherical Torus Experiment (NSTX). [1] An accounting of power balance is needed to properly understand the operation of the divertor so that successful designs can be proposed for future experiments. For this experiment, NSTX, a low aspect ratio spherical torus, was operated at $\mathrm{I}_{\mathrm{p}}=0.6-1.0 \mathrm{MA}, \mathrm{B}_{\mathrm{t}}=0.45 \mathrm{~T}$ in lower singlenull, (LSN) and double-null diverted (DND) configurations. In this paper, the discussion is limited to a scan of injected power from 1 to $6 \mathrm{MW}$, with $\mathrm{I}_{\mathrm{p}}=0.8 \mathrm{MA}$ in LSN and DND Hmode plasmas. H-mode plasmas were chosen because they are routinely produced in NSTX and the good confinement properties represent desirable operating scenarios in high power, long-pulse reactors. Typical discharge conditions of the long-pulse LSN H-mode discharges are shown in Figure 1, generally having occasional large type I ELM's. accompanied by newly observed continuous, small amplitude ELM's, dubbed type V. [2]

A scan of the input heating power was achieved by changing the number of neutral beam sources, while keeping NBI power, plasma current and shape constant. Central electron density was held in a fairly narrow range between 4.0 and $4.7 \times 10^{13} \mathrm{~cm}^{-3}$. Each beam source provides 2.0 MW of injected power when operated at $90 \mathrm{kV}$. Power scans with finer resolution were obtained by modulating the pulse-width in a $50 \%$ duty cycle. To allow thermal equilibration, discharges had to have a minimum of $100 \mathrm{~ms} \mathrm{H}$-mode duration. Divertor $\mathrm{D}_{\alpha}, \mathrm{D}_{\gamma}$ profiles and ion saturation currents measured by the lower divertor tile Langmuir probes suggest that the NSTX inner divertor is detached and the outer divertor is attached. [3] Previous results of heat flux scaling experiments in H-mode LSN diverted configuration in NSTX with 4.5 MW of heating power has reached $10 \mathrm{MW} / \mathrm{m}^{2}$, accounting for more than $80 \%$ of the power to the SOL. Extrapolation of the temperature rise yields a tile temperature in excess of the $1200^{\circ} \mathrm{C}$ limit after 3 s. [4]

In single-null diverted H-mode discharges on DIII-D, the power accountability is more than $85 \%$. Core plasma radiation accounted for $<18 \%$ with the rest flowing through the scrapeoff layer to the inboard and outboard divertors. The total power to the divertor (the power to the 
plates plus the divertor radiation) was split roughly with an in:out ratio of $1: 1.3$. Of the power entering the outboard divertor, $75 \%$ leaves as direct heat flux to the divertor target plates with the remainder radiating in the divertor gas. At the inboard divertor, however, $75 \%$ of the power left as radiation with the rest as divertor target plate heat flux and charge exchange losses. The in/out ratio remained constant over a range of injected power and plasma current and even as divertor conditions changed due to gas puffing. [5]

A preliminary study of power loading, using Langmuir probe data, was recently reported in the MAST device. [6] The in/out power split in DND discharges was quite high (1:9), but qualitatively consistent with NSTX and other devices operating in double-null configurations.

\section{Diagnostics}

Power leaving the plasma is measured by a 16-channel core plasma tangentially viewing bolometer array on the plasma midplane that uses AXUV photodiodes. [7] The reduction in sensitivity of the diodes to photons with less than $30 \mathrm{eV}$ [8] is addressed by examining the electron temperature profile assuming that the energy of the emitted photons is equal to the electron energy. The sensitivity constant to the radiated power from the plasma edge is increased to compensate for the reduction in the responsivity, with this adjustment having the effect of increasing the total radiated power by 30-50\%. Edge diagnostics include two CCD cameras for filtered visible light detection in the divertor and center stack regions [9] and a divertor infrared (IR) camera for divertor heat flux measurements. These are micro-bolometer cameras viewing in the 7-13 $\mu \mathrm{m}$ wavelength range, with a $30 \mathrm{~Hz}$ frame rate and a $25 \mathrm{~ms}$ thermal e-folding time. [10] Recently a "JET style" [11] 4-channel divertor bolometer array was installed, consisting of a $4 \mu \mathrm{m}$ gold foil on a $20 \mathrm{~mm}$ mica substrate that is able to tolerate repeated baking cycles up to $160^{\circ} \mathrm{C}$.

\section{Results}

The input power is calculated using the EFIT equilibrium reconstruction code $[12,13]$ and is defined as $P_{N B}=P_{N B I}+P_{O H}-d W / d t$, where $P_{O H}=$ Ohmic power and $d W / d t=$ time derivative of stored energy in both the poloidal field and the plasma. Approximately $60-70 \%$ of the input power is accounted for, with $15-23 \%$ of power lost as fast ions -- prompt CX, bad 
orbits, and shine through, $23-37 \%$ incident on the divertor plates, $9-14 \%$ radiated in the divertor, and $3-11 \%$ radiated in the main plasma.

The radiation from the main plasma is quite low, never exceeding $350 \mathrm{~kW}$ and accounting for $3-11 \%$ of the input power. This results from the very hollow nature of the radiated power profiles, as shown in Figure 2(a), a consequence of carbon being the principal impurity. No peaked radiation profiles indicative of metallic impurity accumulation are observed in any condition. Because the emission is primarily from $\mathrm{C}^{+}$to $\mathrm{C}^{+3}$, which emits in the $10-40 \mathrm{eV}$ range, the radiating region is located at the low-density $\left(1-2 \times 10^{13} / \mathrm{cm}^{3}\right)$ edge of the NSTX plasma, typically $3 \mathrm{~cm}$ inside the separatrix calculated by EFIT. Using a coronal equilibrium model, with a reduced $\mathrm{T}_{\mathrm{e}}$ to account for transport, the carbon concentration at the edge required to emit even this modest amount is calculated to be as high as $10 \%$, so the low total radiation from the main plasma is reasonable for a device with graphite plasmas-facing components. This high edge carbon concentration is confirmed with CXR measurements, Bremsstrahlung, and spectroscopy using AXUV diodes filtered with thin metal windows.

Perhaps more surprising is the fact that the total radiated power decreases by almost a factor of 3 with increasing input power. This can be seen in Figure 2(b) with the obvious exception of the points with the net input power of $1 \mathrm{MW}$. These two discharges are distinguished from the remainder in that at the time of interest (from $.3-.34$ seconds) the stored energy in the magnetic field is increasing substantially, accounting for about $60 \%$ of the input power. For the remainder of the points, the increase in magnetic stored energy is only a few percent of the input power. The principal trend towards decreasing radiated power in the main plasma with increasing input power cannot be explained by density changes, either on average or in the edge region where the carbon is radiating. Thomson scattering density profiles show that in this range of input power, the line-averaged density varies in a narrow range: from 4 to $4.5 \times 10^{13} / \mathrm{cm}^{3}$ and the edge density only between 1.7 and $2 \times 10^{13} / \mathrm{cm}^{3}$. There is no discernable trend towards lower density inside this range, and if there were, it would still account for only a $25 \%$ drop in radiated power, not a factor of three. A possible source of error is the assumptions necessary to volume integrate the midplane bolometer data. Values for $\psi$, the poloidal flux function are obtained from EFIT equilibrium reconstructions and the midplane data is projected 
along poloidal flux contours, assuming that the radiated power is a constant along a surface of constant- $\psi$. Though a good assumption in the plasma core, it is often a poor one for the plasma edge where the bulk of the radiation originates. The radiated power profiles are not symmetric on NSTX with in/out ratios along the same $\psi$-surface seen as high as 10:1. An example of a preponderance of radiation coming from the inboard side for a $4 \mathrm{MW} \mathrm{NBI}$ shot is seen in Figure 2(a).

The largest fraction of the input power flows through the scrape-off layer to the inboard and outboard divertors. Peak heat flux to the outer divertor strike plates scales with injected power and is as high as $7 \mathrm{MW} / \mathrm{m}^{2}$ with $6 \mathrm{MW}$ and is typically 3-4 times the peak heat flux to the inner divertor. The area-integrated total heat to the divertor represents about $30-45 \%$ of the input power and rises generally linearly with input power as shown in Figure 3. Note however that the peak heat flux was observed to increase non-linearly with NBI power, similar to that found in prior experiments. [4] This was found to result from the edge temperature, which increases with NBI power and tends to shrink the SOL width, so the heat flux increases rapidly compared to the total heat to the plates. In LSN discharges, the in/out power split shows that $75-80 \%$ of the heat incident on the outer strike plate, i.e., the ratio is 1:4. Like the total radiated power, again the exception is the low input power shots, where this ratio is about 1:15. In DND discharges the power split is approximately 1:9, similar to the MAST results mentioned previously.

The measured surface brightness from divertor bolometry increases linearly with input power and reaches about $0.28 \mathrm{MW} / \mathrm{m}^{2}$ at $6.3 \mathrm{MW}$ of input power. This is about $20 \%$ of the heat flux to the inner divertor plate and 20 times less than the heat flux to the outer divertor plate. Because the radiated flux is so much less than the heat flux to the plates, it does not appear that the divertor radiation can significantly compensate for the strong in/out asymmetry in the divertor plate power, i.e., partly equalizing the power flow between the divertor plates as was observed in DIII-D. [5] Because the divertor bolometer has only horizontally viewing channels, the major radius of the radiating volume is not directly measured, and only an estimate of the total power can be gleaned from the surface brightness. Using the assumption that the emitting volume is located mid-way between the " $\mathrm{X}$ " point and the outboard strike 
point, the power radiated in the divertor is calculated to be $10-15 \%$ of the input power, as shown in Figure 3. Because the total power scales with the major radius of the emitting volume, were it located at the inboard strike point, the power radiated in the divertor would be decreased by a factor of two.

Fast ion losses were not directly measured, but were calculated using the TRANSP code, showing that a significant fraction (10-20\%) of input power is lost due to three processes:

- beam shine-through to the neutral beam armor (40\% of the fast ion losses),

- prompt CX (10\%), which is distributed primarily to the outer wall

- and bad orbit losses (50\%), distributed primarily to the RF antenna limiter

\section{Discussion}

A number of observations suggest that the remainder of the power is likely to be found in the upper divertor region. An abbreviated power scan in otherwise similar DND discharges shows about $50-60 \%$ of the lost power flowing to the divertors (assuming up/down symmetry) and about $85 \%$ total power accountability. This was calculated by doubling the power radiated in the divertor and the heat to the strike plates to account for the upper divertor region. Another indication is that EFIT's drsep parameter, the position of secondary x-point (in the upper divertor), as projected along a poloidal flux contour to the midplane, was about $1.2 \mathrm{~cm}$ away from the primary x-point. Previous LSN discharges (with a drsep value near $2 \mathrm{~cm}$ ) showed 60$70 \%$ of loss power flowing into the lower divertor. [3] If the $d r s e p$ parameter is reduced to the point where it approaches the width of the SOL power flux at the midplane, then heat and particles can flow into the upper divertor area as well. We note that the power accountability for the LSN discharges improved when the plasma current was increased, which is believed to reduce the width of the SOL power flux at the midplane.

A simple way to estimate the magnitude of this effect is to compare divertor data in DND and LSN plasmas. Ideally, the power to the divertor (strike plates and/or radiating neutrals) in the DND configuration should be half the power measured in the corresponding LSN configuration. If the power is reduced by less than $50 \%$, it likely indicates that substantial power flows to the region of the secondary x-point. The divertor bolometers consistently recorded a 40-50\% drop in radiated power in the DND plasmas, i.e., only a minor shortfall. 
The main indication came from the heat to the divertor plates, which showed only a $25-30 \%$ decrease in DND. This suggests that nearly $50 \%$ of the divertor heat flux observed in the lower divertor might well be incident on the upper divertor plates. A composite plot of these measurements and calculations is shown in Figure 4, where the power to the upper divertor was estimated by compensating for the for power flow to the upper divertor by multiplying the heat to the divertor plates by 1.5 , and the radiated power in the divertor by 1.1. As the figure shows, the power accountability for the LSN discharges is brought into the 80-90\% range as well.

In summary, we account for the power in the DND configurations and find it to be nearly equal to the net input power. The power accountability in LSN configuration is only 60$70 \%$, but we postulate that the remaining power flows to the upper divertor due to a projected separation between the primary and secondary " $\mathrm{X}$ " point that is comparable to the power flux SOL width, i.e., $d r s e p \approx d^{P F}{ }_{S O L}$. An additional IR camera will be installed to view the upper divertor region to measure the power balance as a function of drsep. The uncertainty in the volume integration of the radiated power in the divertor will be addressed by using a CIII filter on a newly installed divertor visible camera to determine the radial distribution of the radiated power. Also, additional divertor bolometer channels will ascertain the vertical extent of the divertor radiation. Finally the existing ultra-soft X-ray system can be used to assess the poloidal asymmetry in the radiated power from the main chamber .

\section{Acknowledgements}

Work supported by US Department of Energy contracts DE-AC02-76CH03073, DEAC05-00OR22725 and W-7405-ENG-48. The authors gratefully acknowledge the contributions of the NSTX technical staff. 


\section{Figure Captions}

Figure 1. Operating conditions for the LSN power scan in H-modes. The plasma current is in amperes, the Injected power is in $\mathrm{MW}$, and the $\mathrm{D}_{\alpha}$ signal is in arbitrary units. This plasma (shot \#112499) had a nominal NBI power of $6 \mathrm{MW}$ and a plasma current of $0.8 \mathrm{MA}$. The H-mode transition occurred at $0.22 \mathrm{sec}$ and the first type I ELM occurred at $0.34 \mathrm{sec}$.

Figure 2. (a) Time evolution of the radiated power density profile from the mid-plane bolometer for a 4 MW NBI discharge (shot \#112498). (b) Total radiated power from the main plasma as a function of input power. Input power is Ohmic Heating + injected power - the time derivative of the stored energy (kinetic plus magnetic.) The power density measurement error is dominated by systematic contributions, which are estimated to be less than $\pm 10 \%$. The volume integration depends on an assumption of poloidal symmetry. Given the in/out profile asymmetry, this error could be greater than $50 \%$.

Figure 3.Total heating power incident on both the inner and outer lower divertor plates is shown by the 's The estimated error resulting from the analysis technique is $\pm 15 \%$. Surface integrated radiated power flux in the lower divertor is shown by the $\diamond$ 's. Systematic errors in measuring the flux are less than $10 \%$. However, because of uncertainties in the radial location of the emitting layer, the error in surface integration could reduce the total divertor radiated power by as much as $50 \%$.

Figure 4. Incremental contributions to the total accounted power for the H-mode power scan in LSN, including the estimate of power to the upper divertor region. The open squares $(\square)$ depict the heat flow to the divertor plates. The increment between the $\square$ 's and the $\times$ 's represent the divertor radiation. The increment between the $\times$ 's and the triangles $(\triangle)$ is due to radiation from the main plasma and the energy expended in orbit losses is shown by the increment between the $\triangle$ 's and the 's. The 's represent the total accounted power. 

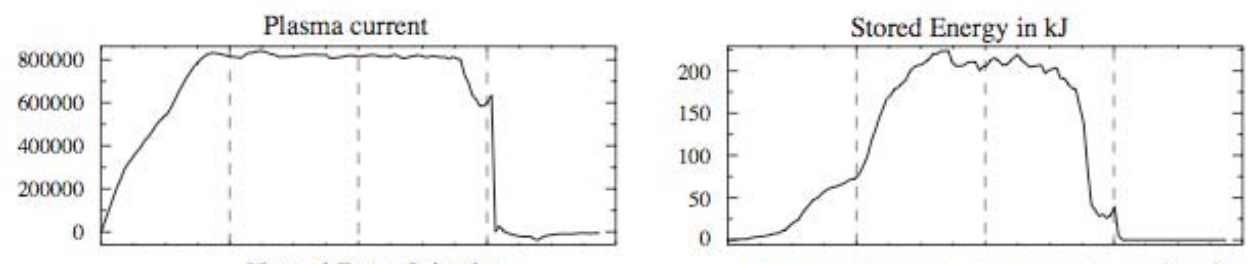

Neutral Beam Injection

Thomson Scattering Line Density $\left(10^{15} / \mathrm{cm}^{2}\right)$
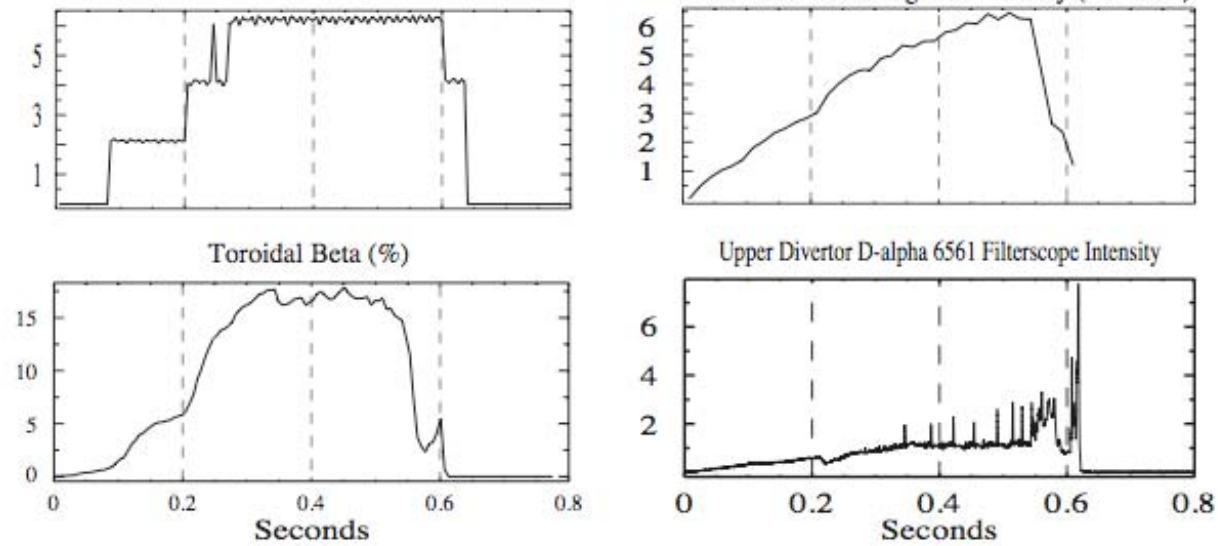

Figure 1 


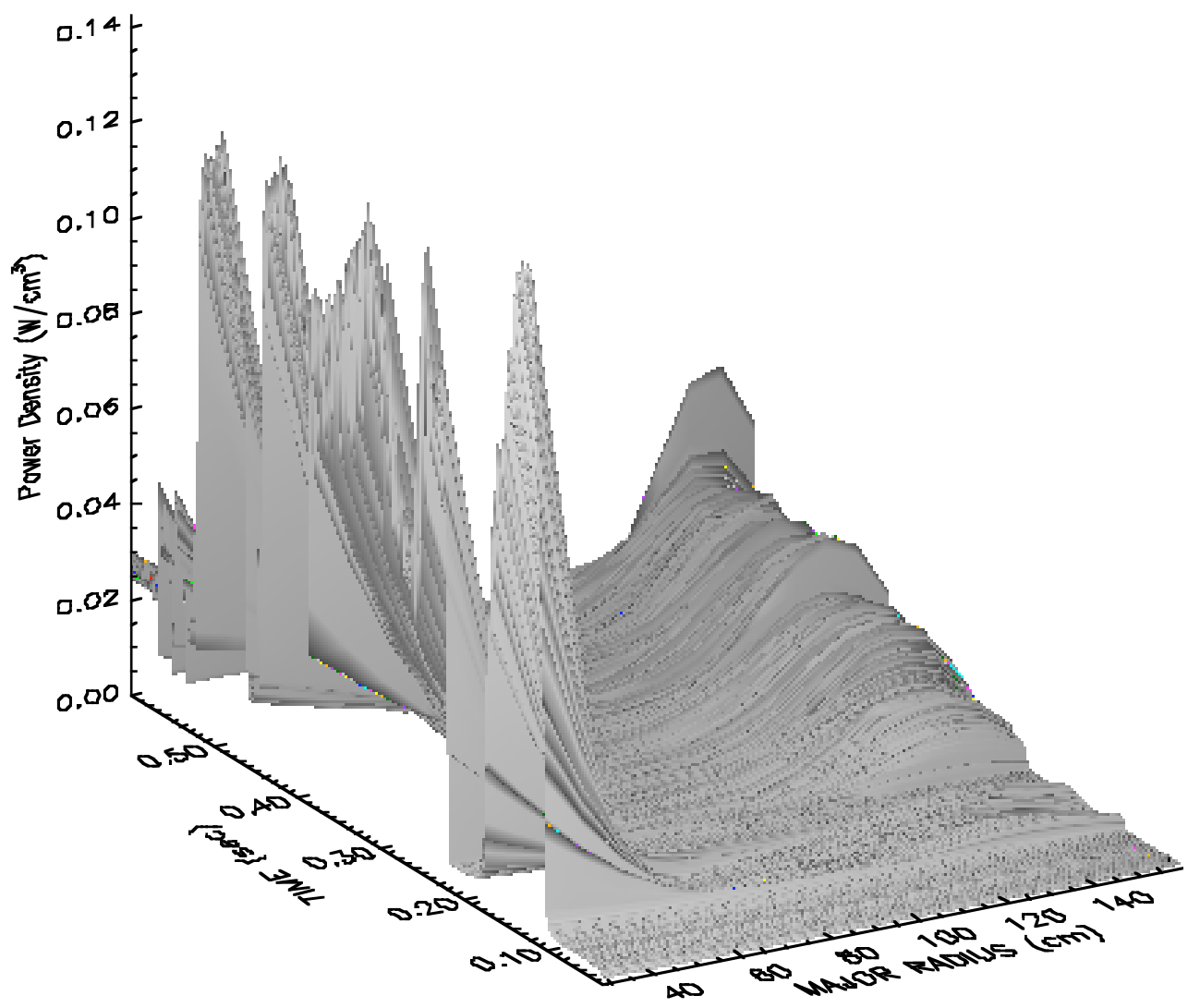

(a)

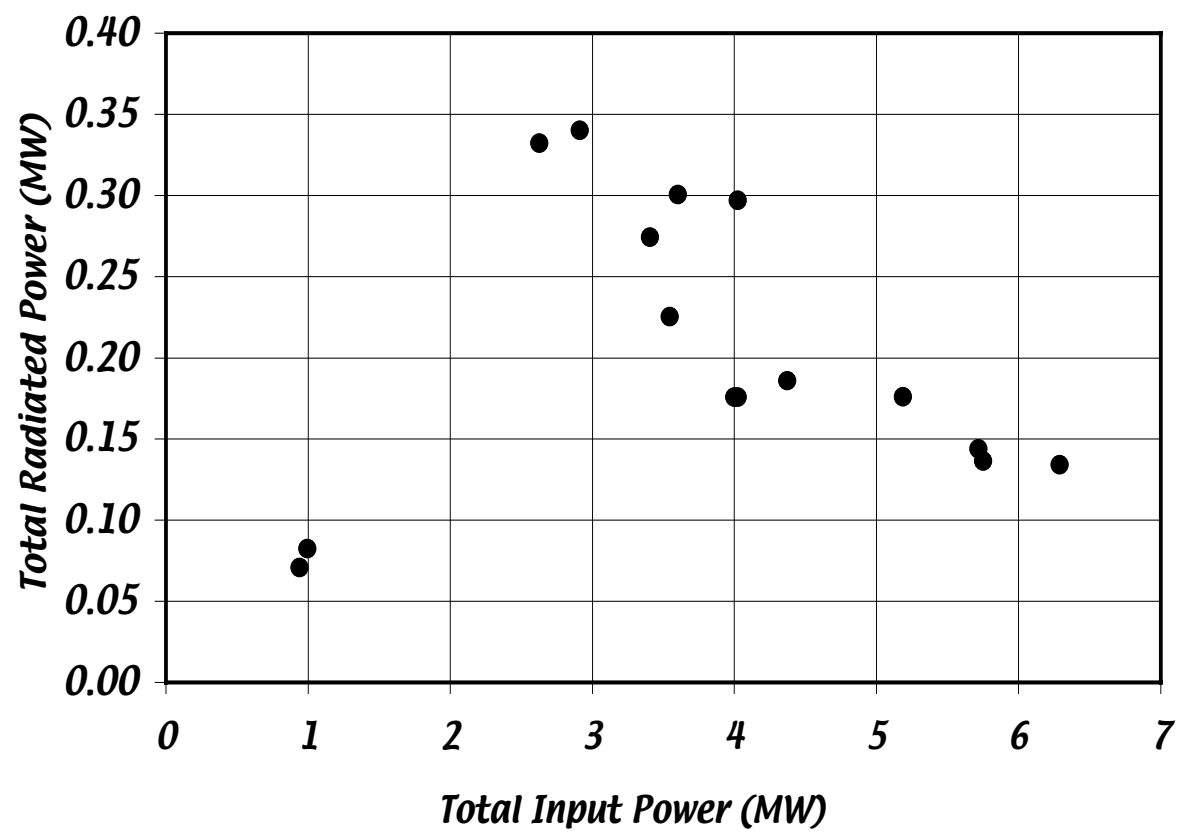

(b)

Figure 2 


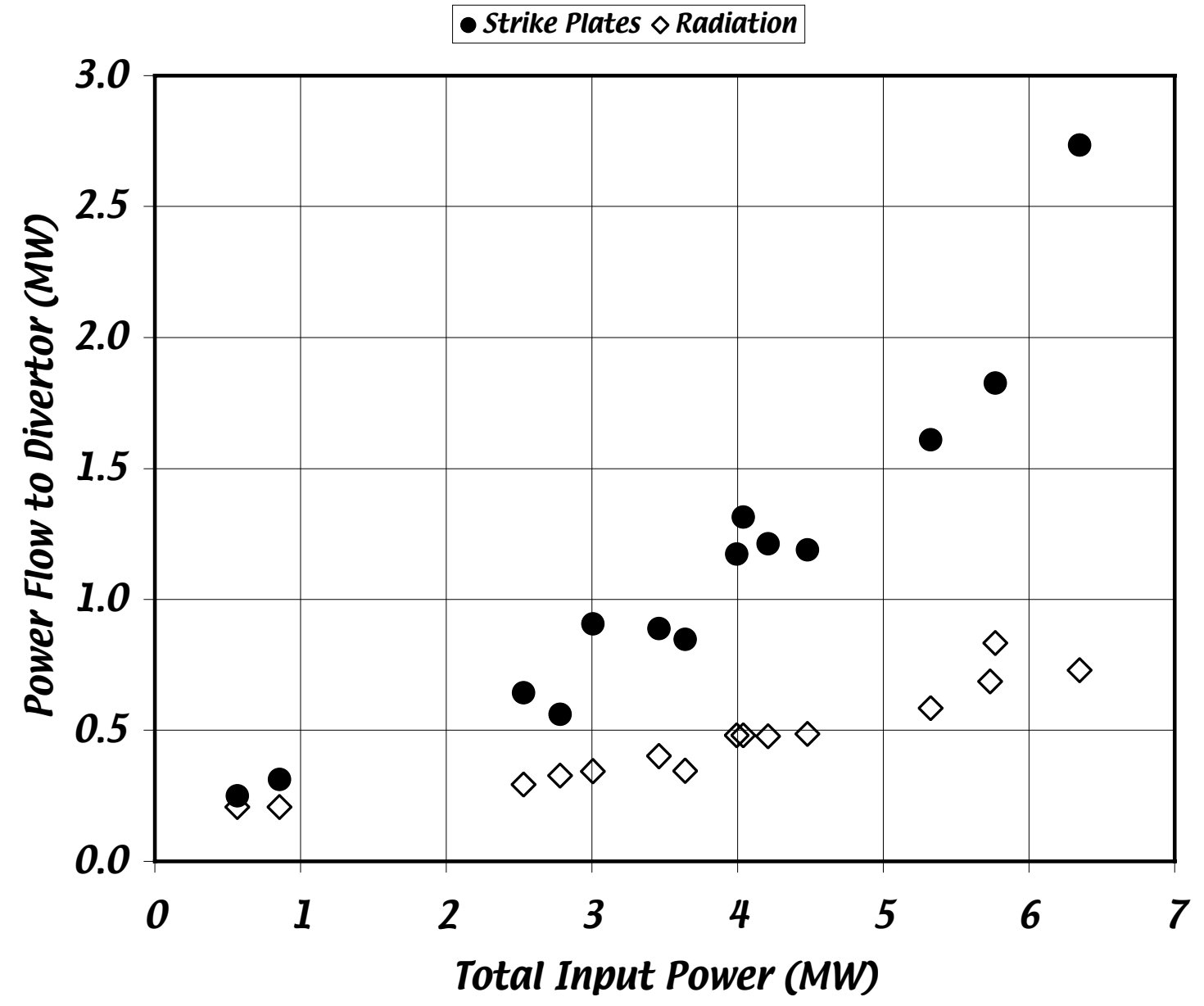

Figure 3. 


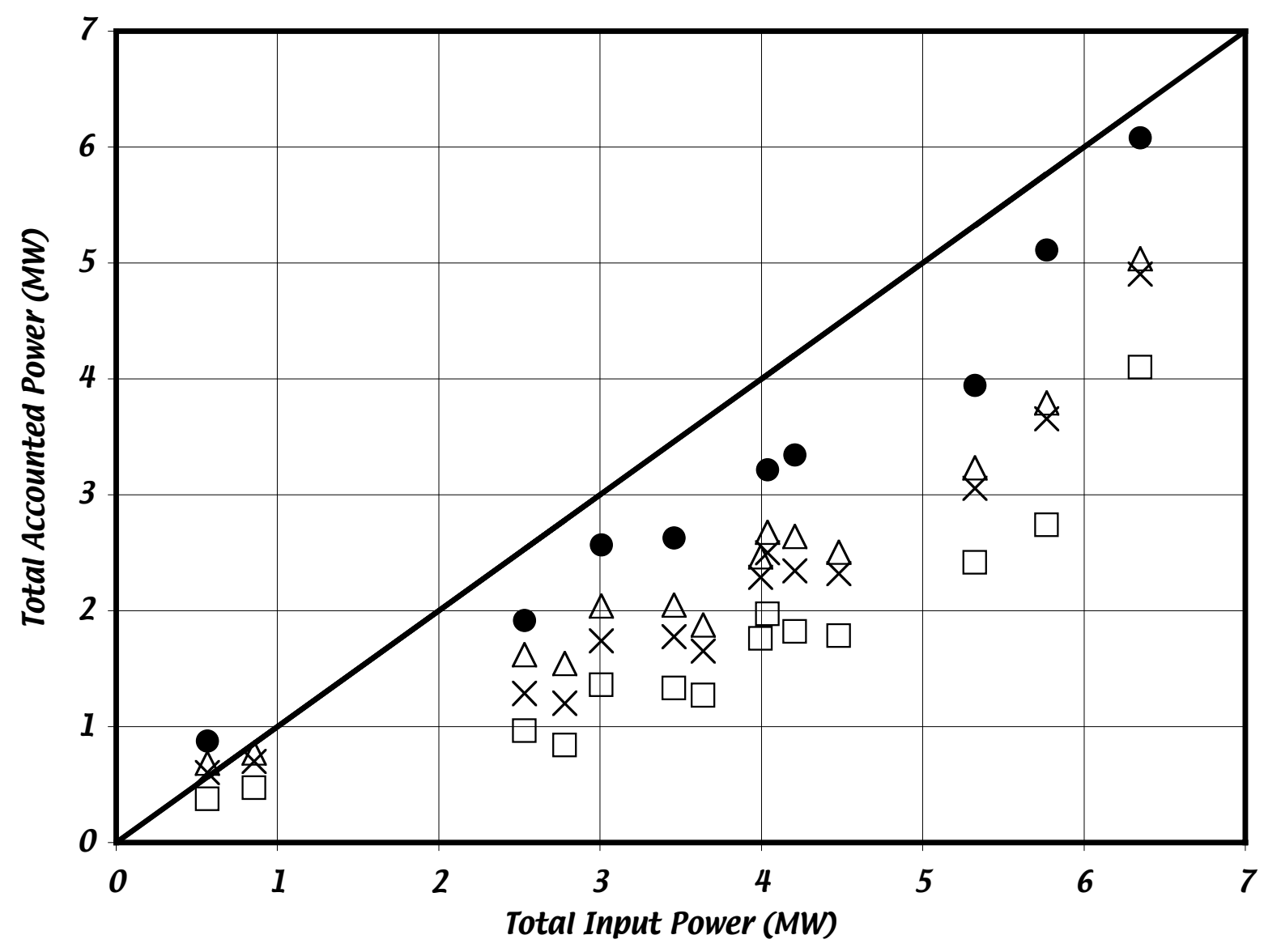

Figure 4. 


\section{References}

[1] M. Ono, et al., Nucl. Fusion, 40, 557 (2000).

[2] R. Maingi, R.E. Bell, C.E. Bush, et al., these proceedings.

[3] V. A. Soukhanovskii, R. Maingi, C. Bush, et al., these proceedings.

[4] R. Maingi, M. G. Bell, R E Bell, et al., Plasma Phys. Ctrl. Fusion, 45, 657-669 (2003) .

[5] A.W. Leonard, C.J. Lasnier, J.W. Cuthbertson, et. al., J. Nucl. Mater., 220-222, 325 (1995).

[6] J.-W. Ahn et al., J. Nucl. Mater., 290-293, 820 (2001).

[7] S. Paul, D. Johnson, J. Robinson, et al., Bull. Amer. Phys. Soc., 44, Paper JP1.103 (1999).

[8] R.L. Boivin, J.A. Goetz, E.S. Marmar, et al., Rev. Sci. Instrum.,70 (1), 260-264 (1999).

[9] V. A. Soukhanovskii, A. L. Roquemore, C. H. Skinner, et. al., Rev. Sci. Instrum. 74, 2094 (2003).

[10] D. Mastrovito, R. Maingi, H. W. Kugel, et al., Rev. Sci. Instrum., 74, 5090 (2003).

[11] K. F. Mast and H. Krause, Rev. Sci. Instrum., 56 (5), 969 (1985).

[12] L. L. Lao, et. al., Nuclear Fusion 25, 1611 (1985).

[13] S. A. Sabbagh, et. al., Nuclear Fusion 41, 1601 (2001). 



\section{External Distribution}

Plasma Research Laboratory, Australian National University, Australia

Professor I.R. Jones, Flinders University, Australia

Professor João Canalle, Instituto de Fisica DEQ/IF - UERJ, Brazil

Mr. Gerson O. Ludwig, Instituto Nacional de Pesquisas, Brazil

Dr. P.H. Sakanaka, Instituto Fisica, Brazil

The Librarian, Culham Laboratory, England

Mrs. S.A. Hutchinson, JET Library, England

Professor M.N. Bussac, Ecole Polytechnique, France

Librarian, Max-Planck-Institut für Plasmaphysik, Germany

Jolan Moldvai, Reports Library, Hungarian Academy of Sciences, Central Research Institute for Physics, Hungary

Dr. P. Kaw, Institute for Plasma Research, India

Ms. P.J. Pathak, Librarian, Institute for Plasma Research, India

Ms. Clelia De Palo, Associazione EURATOM-ENEA, Italy

Dr. G. Grosso, Instituto di Fisica del Plasma, Italy

Librarian, Naka Fusion Research Establishment, JAERI, Japan

Library, Laboratory for Complex Energy Processes, Institute for Advanced Study, Kyoto University, Japan

Research Information Center, National Institute for Fusion Science, Japan

Dr. O. Mitarai, Kyushu Tokai University, Japan

Dr. Jiangang Li, Institute of Plasma Physics, Chinese Academy of Sciences, People's Republic of China

Professor Yuping Huo, School of Physical Science and Technology, People's Republic of China

Library, Academia Sinica, Institute of Plasma Physics, People's Republic of China

Librarian, Institute of Physics, Chinese Academy of Sciences, People's Republic of China

Dr. S. Mirnov, TRINITI, Troitsk, Russian Federation, Russia

Dr. V.S. Strelkov, Kurchatov Institute, Russian Federation, Russia

Professor Peter Lukac, Katedra Fyziky Plazmy MFF UK, Mlynska dolina F-2, Komenskeho Univerzita, SK-842 15 Bratislava, Slovakia

Dr. G.S. Lee, Korea Basic Science Institute, South Korea

Institute for Plasma Research, University of Maryland, USA

Librarian, Fusion Energy Division, Oak Ridge National Laboratory, USA

Librarian, Institute of Fusion Studies, University of Texas, USA

Librarian, Magnetic Fusion Program, Lawrence Livermore National Laboratory, USA

Library, General Atomics, USA

Plasma Physics Group, Fusion Energy Research Program, University of California at San Diego, USA

Plasma Physics Library, Columbia University, USA

Alkesh Punjabi, Center for Fusion Research and Training, Hampton University, USA

Dr. W.M. Stacey, Fusion Research Center, Georgia Institute of Technology, USA

Dr. John Willis, U.S. Department of Energy, Office of Fusion Energy Sciences, USA

Mr. Paul H. Wright, Indianapolis, Indiana, USA 
The Princeton Plasma Physics Laboratory is operated by Princeton University under contract with the U.S. Department of Energy.

\author{
Information Services \\ Princeton Plasma Physics Laboratory \\ P.O. Box 451 \\ Princeton, NJ 08543
}

Phone: 609-243-2750

Fax: 609-243-2751

e-mail: pppl_info@pppl.gov

Internet Address: http://www.pppl.gov 